\title{
Sequential Extraction of Some Heavy Metals in Haihe River Sediments, People's Republic of China
}

\author{
C. Yuan, ${ }^{1}$ G. Jiang, ${ }^{1}$ L. Liang, ${ }^{1}$ X. Jin, ${ }^{2}$ J. Shi ${ }^{1}$ \\ 1 Key Laboratory of Environmental Chemistry and Ecotoxicology, Research Center \\ for Eco-Environmental Sciences, Chinese Academy of Sciences, Post Office Box \\ 2871, 100085 Beijing, People's Republic of China \\ 2 College of Environmental Science and Engineering, Nankai University, 300071 \\ Tianjin, People's Republic of China
}

Received: 15 September 2003/Accepted: 21 April 2004

Metals can not be always fixed by sediments permanently, and they may be recycled via the biological and chemical agents, both within the sedimentary compartment and back to the water body. The changes in the environment conditions, such as acidification, redox potential conditions or increases in the organic ligand concentrations can cause the trace elements mobilization. As a sink and source, sediment constitute reservoir of the bioavailable trace elements and plays an important role in the geo-chemical cycles. So the investigation of heavy metal concentration in sediments is very important. However, the total concentration of metals can not provide sufficient information because the mobility, bioavailability and toxicity of metals depends not only on their total concentration but on the physicochemical form in which they occur.

Sequential extraction (SE) proposed by Tessier et al (1979) and Kersten (1986) provides more information about mobility, bioavailability and toxicity of metals. Following these two basic schemes, some modified procedures including the BCR method (Ure, 1993) were developed with the different sequences of reagents used or the modified operational conditions. In this study, the exchangeable fraction and the carbonate fraction were considered respectively. A developed five-step sequential extraction procedure was proposed based on the BCR and Kersten scheme. According to the proposed method, metals in sediments were separated into five different fractions, which could be described as exchangeable, carbonate, iron and manganese oxides, sulfides and organic matter, residue fractions. This sequential extraction scheme can provide the information about the extent that trace metals bound to the binding sites in sediments and help us in understanding geochemical processes of trace metals.

Haihe River is a famous river in north China and locates in Tianjin area. Tianjin city has a long history as an industrial city with a population of 9.16 million. Haihe River receives input of industrial, domestic and agricultural effluents from the cities and sends them into the Bohai Sea at the Tanggu influx. In our study, eight sampling sites were selected along Haihe River and the sediment samples were submitted to the proposed sequential extraction procedure to obtain the distribution patterns of metals. The sampling locations for the study were indicated in Figure 1. 


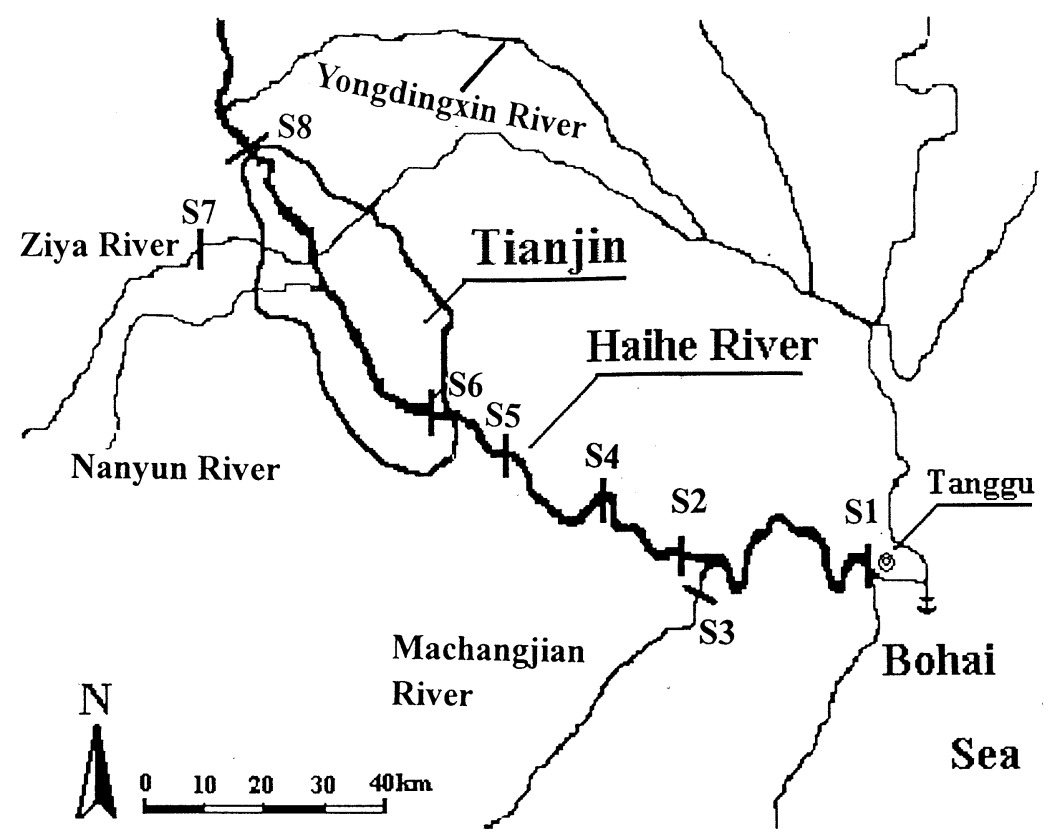

Figure 1. Map of study area and sampling sites.

\section{MATERIALS AND METHODS}

Elements were determined by graphite furnace atomic absorption spectrometry using a Hitachi Z5700 Polarized Zeeman spectrometer, equipped with single element hollow-cathode lamps and autosampler. Zeenman background correction was used for all analyses in the experiment. Palladium modification (200 $\left.\mathrm{mg} \mathrm{l}^{-1}\right)$ was preferred for the determination of cadmium and lead. Analytes were determined at the following wavelengths (nm): $\mathrm{Cd} 228.8$; $\mathrm{Cu} 32 \% .4 ; \mathrm{Mn} 280.1$; Co 240.7; Ni 232.0; Pb 283.3.

A horizontal rotator shaker was used for the extraction. The extract was centrifuged at $4000 \mathrm{r} / \mathrm{min}$ for $20 \mathrm{~min}$ by using a centrifuge. All the glass containers used in the experiment were marinated in $50 \%(\mathrm{~V} / \mathrm{V})$ nitric acid and rinsed with deionized water three times. The extracts from the samples were stored in PTFE tubes at $4^{\circ} \mathrm{C}$ in a refrigerator before analysis.

A five step sequential extraction procedure was developed and applied to determine the concentration of $\mathrm{Cd}, \mathrm{Mn}, \mathrm{Cu}, \mathrm{Co}, \mathrm{Ni}$ and $\mathrm{Pb}$ in the river sediments. The sequential extraction procedure is illustrated as follows:

$20 \mathrm{ml} \cdot 1 \mathrm{M} \mathrm{NH} \mathrm{NHAc}_{4}$ at initial $\mathrm{pH} 7$ was added to $0.5 \mathrm{~g}$ dry sediment in a $50 \mathrm{ml}$ centrifuge tube. The mixture was shaken for $2 \mathrm{~h}$ at room temperature.

$20 \mathrm{ml}$ volume $1 \mathrm{M} \mathrm{NaOAc}$ buffered to $\mathrm{pH} 5.0$ with HOAc was added to the residue from the above step and stirred for $5 \mathrm{~h}$ at room temperature. 
The residue from step two was extracted with $20 \mathrm{ml} 0.1 \mathrm{M} \mathrm{NH} \mathrm{NH}_{4} \mathrm{OH} \cdot \mathrm{HCl}$ (adjusted to $\mathrm{pH} 2$ with $\mathrm{HNO}_{3}$ ). The tube was then shaken for $16 \mathrm{~h}$ at room temperature.

$5 \mathrm{ml} 30 \% \mathrm{H}_{2} \mathrm{O}_{2}\left(\mathrm{pH} 2.0\right.$ adjusted with $\mathrm{HNO}_{3}$ ) was added to the residue from step three. The digestion procedure lasted for $1 \mathrm{~h}$ at room temperature with occasional manual shaking. Then the centrifuge tube was put into a $85^{\circ} \mathrm{C}$ water bath for $1 \mathrm{~h}$. A second $5 \mathrm{ml}$ aliquot of $\mathrm{H}_{2} \mathrm{O}_{2}$ was added and the tube was again heated to $85^{\circ} \mathrm{C}$ for $1 \mathrm{~h}$. $20 \mathrm{ml} 1 \mathrm{M} \mathrm{NH} \mathrm{m}_{4} \mathrm{OAc}$ (adjusted to $\mathrm{pH} 2.0$ with $\mathrm{HNO}_{3}$ ) was added to the cool, moist residue. Then the tube was shaken for $16 \mathrm{~h}$ at room temperature.

The residue from step four was freeze-dried and $0.1000 \mathrm{~g}$ (dry weight) of residue was weighted into a $30 \mathrm{ml}$ Teflon container with seal and then $2 \mathrm{ml}$ concentrated $\mathrm{HNO}_{3}, 0.5 \mathrm{ml} \mathrm{HF}$ were added in sequence. The container was heated at $180^{\circ} \mathrm{C}$ for $8 \mathrm{~h}$.

At the end of each extraction step, the extract was separated by centrifugation and $10 \mathrm{ml}$ deionzed water was used to wash the residue by shaking for $15 \mathrm{~min}$. Then the tube was centrifuged, and the supernatant was decanted. To obtain the total concentration of elements in the samples, the total digestion procedure similar with the fifth step was applied. Compared to the fifth step extraction, $2 \mathrm{ml}$ hydrogen peroxide was added to accelerate destruction of organic components in samples during the total digestion procedure.

\section{RESULTS AND DISCUSSION}

In order to evaluate the recovery and precision of the extraction procedure, a stream sediment reference material (GBW07310) was employed during the curse of sequential extraction. Table 1 and Table 2 indicate that the proposed sequential extraction procedure is repeatable and reliable with acceptable standard deviation and good recoveries (93.8-118.8\%). The results of the Haihe river sediment samples obtained from the proposed sequential extraction scheme are listed in Table 3.

Exchangeable fraction (F1): The metals in this fraction mean that they can be released easily by ion-exchange process. Usually the weakly-sorbed metal species, particularly those retained on the sediment surface by relatively weakly electrostatic interactions, are included in this operation fraction. Heavy metal concentration in the exchangeable fraction play a very important role in the evaluation of environment and always act as a pollution indicator (Forstner and Wittmann, 1979) for its environmental mobility and bioavailability. In our experiment, most of elements studied in this fraction were in very small section. For example, although $50.48 \mu \mathrm{g} \mathrm{g}^{-1}$ lead was found at sampling site $\mathrm{S} 5$, the concentration occurred in the exchangeable fraction was only $0.01 \mu \mathrm{g} \mathrm{g}^{-1}$ (account for $0.02 \%$ of total concentration).

The proportion of the exchangeable fraction was $\mathrm{Cd} 2.4-6.5 \%, \mathrm{Cu} 0.6-4.1 \%, \mathrm{Co}$ $0-1.3 \%$, Ni $0.8-4.2 \%$ respectively. Relative higher proportion in this fraction was 
found in distribution of $\mathrm{Mn}$, which $5.8-13.0 \%$ of the total concentration was found in exchangeable fraction. The results from the study indicate that the river was not polluted seriously according to Forstner and Wittmann's criterion. The distribution patterns agree with the observation of Surija and Branica(1995). In their study, the distribution of $\mathrm{Cd}, \mathrm{Pb}$ and $\mathrm{Cu}$ in the exchangeable fraction was negligible. The similar results were also obtained by Stalikas et al. (1999) who used $0.05 \mathrm{M}$ EDTA solution as the extraction regent for metals in the exchangeable fraction and found that the concentrations of metals in the phase were very low in general.

Carbonate fraction (F2): The metals occurred in this fraction may be thought to have been present as co-precipitated with carbonate minerals and is sensitive to $\mathrm{pH}$ changes, and metal release is achieved through dissolution of a fraction of the solid material at $\mathrm{pH}$ close to 5 . In this work, a buffered acetic acid and sodium acetate was applied to achieve the information of the metal concentration in this

Table 1. Standard deviation of the proposed five-step sequential extraction procedure ( $\mu \mathrm{g} \mathrm{g}^{-1}$ dry weight, $\left.\mathrm{n}=5\right)$.

\begin{tabular}{llllll}
\hline \multirow{2}{*}{ Element } & \multicolumn{5}{c}{ Fraction } \\
\cline { 2 - 6 } & $\mathrm{F} 1$ & $\mathrm{~F} 2$ & $\mathrm{~F} 3$ & $\mathrm{~F} 4$ & F5 \\
\hline $\mathrm{Cd}$ & $0.082 \pm$ & $0.24 \pm$ & $0.34 \pm$ & $0.16 \pm$ & $0.19 \pm$ \\
& 0.009 & 0.058 & 0.028 & 0.006 & 0.026 \\
$\mathrm{Cu}$ & $0.120 \pm$ & $1.01 \pm$ & $0.07 \pm$ & $1.62 \pm$ & $17.06 \pm$ \\
& 0.016 & 0.062 & 0.005 & 0.19 & 1.06 \\
$\mathrm{Co}$ & $0.030 \pm$ & $0.41 \pm$ & $3.26 \pm$ & $8.01 \pm$ & $5.34 \pm$ \\
& 0.006 & 0.05 & 0.27 & 0.36 & 0.28 \\
$\mathrm{Ni}$ & $0.195 \pm$ & $1.40 \pm$ & $10.45 \pm$ & $7.95 \pm$ & $11.26 \pm$ \\
& 0.019 & 0.106 & 1.23 & 0.69 & 0.65 \\
$\mathrm{Mn}$ & $8.13 \pm$ & $101.30 \pm$ & $318.36 \pm$ & $106.57 \pm$ & $556.60 \pm$ \\
& 0.69 & 8.25 & 12.97 & 9.65 & 39.85 \\
$\mathrm{~Pb}$ & $0.023 \pm$ & $0.38 \pm$ & $11.01 \pm$ & $7.26 \pm$ & $10.56 \pm$ \\
& 0.002 & 0.021 & 1.6 & 0.63 & 0.87 \\
\hline
\end{tabular}

Table 2. Recovery of the proposed five-step sequential extraction procedure $(\mu \mathrm{g}$ $\mathrm{g}^{-1}$ dry weight, $\mathrm{n}=5$ ).

\begin{tabular}{lllll}
\hline Element & Total & Reference value & $\begin{array}{c}\text { Recovery }^{\mathrm{a}} \\
(1)\end{array}$ & $\begin{array}{c}\text { Recovery }^{\mathrm{b}} \\
(2)\end{array}$ \\
\hline $\mathrm{Cd}$ & $1.05 \pm 0.087$ & $1.12 \pm 0.12$ & 96.4 & 93.8 \\
$\mathrm{Cu}$ & $23.15 \pm 1.24$ & $22.6 \pm 2.0$ & 85.9 & 102.4 \\
$\mathrm{Co}$ & $18.17 \pm 0.56$ & $15.3 \pm 1.7$ & 93.9 & 118.8 \\
$\mathrm{Ni}$ & $29.89 \pm 1.68$ & $30.2 \pm 2.6$ & 104.6 & 99.0 \\
$\mathrm{Mn}$ & $1009.90 \pm 69.45$ & $1013 \pm 44$ & 108.0 & 99.7 \\
$\mathrm{~Pb}$ & $28.14 \pm 1.32$ & $27 \pm 3.0$ & 103.9 & 104.2 \\
\hline
\end{tabular}

${ }^{a}$ Recovery $(1)=\left(\mathrm{C}_{\mathrm{F}-1}+\mathrm{C}_{\mathrm{F}-2}+\mathrm{C}_{\mathrm{F}-3}+\mathrm{C}_{\mathrm{F}-4}+\mathrm{C}_{\mathrm{F}-5}\right) / \mathrm{C}_{\text {Total }}$, given in percentage $(\%)$

${ }^{\mathrm{b}}$ Recovery $(2)=\mathrm{C}_{\text {Total }} / \mathrm{C}_{\text {Reference value, given in percentage }(\%)}$ 
Table 3. Sequential extraction results for the sediment samples from Haihe River ( $\mu \mathrm{g} \mathrm{g}^{-1}$ dry weight).

\begin{tabular}{|c|c|c|c|c|c|c|c|}
\hline Site & Fraction & $\mathrm{Cu}$ & $\mathrm{Mn}$ & Co & $\mathrm{Ni}$ & $\mathrm{Pb}$ & $\mathrm{Cd}$ \\
\hline \multirow[t]{5}{*}{ S1 } & F1 & 1.52 & 79.92 & 0.18 & 1.07 & 0.04 & 0.05 \\
\hline & F2 & 2.55 & 199.23 & 1.97 & 3.63 & 1.25 & 0.10 \\
\hline & F3 & 0.12 & 56.77 & 1.92 & 5.03 & 0.23 & 0.22 \\
\hline & F4 & 2.67 & 36.13 & 2.99 & 9.92 & 3.70 & 0.44 \\
\hline & F5 & 40.26 & 485.26 & 14.56 & 15.62 & 30.11 & 0.76 \\
\hline \multirow[t]{5}{*}{ S2 } & F1 & 0.46 & 64.02 & 0.09 & 0.38 & 0.02 & 0.04 \\
\hline & $\mathrm{F} 2$ & 0.82 & 114.23 & 1.28 & 1.80 & 1.21 & 0.10 \\
\hline & F3 & 0.02 & 22.62 & 1.66 & 2.87 & 0.06 & 0.14 \\
\hline & F4 & 1.02 & 35.25 & 1.77 & 5.28 & 3.02 & 0.15 \\
\hline & F5 & 25.68 & 592.36 & 12.38 & 24.88 & 26.02 & 0.61 \\
\hline \multirow[t]{5}{*}{$\mathrm{S} 3$} & F1 & 0.52 & 76.50 & 0.07 & 1.40 & 0.01 & 0.03 \\
\hline & F2 & 0.91 & 200.00 & 1.52 & 4.19 & 1.34 & 0.09 \\
\hline & F3 & 0.02 & 41.91 & 1.29 & 3.99 & 0.07 & 0.21 \\
\hline & F4 & 1.04 & 24.03 & 1.66 & 7.03 & 3.32 & 0.11 \\
\hline & F5 & 28.89 & 456.66 & 12.86 & 19.26 & 14.01 & 0.60 \\
\hline \multirow[t]{5}{*}{ S4 } & $\mathrm{F} 1$ & 1.27 & 92.70 & 0.21 & 1.05 & 0.01 & 0.04 \\
\hline & F2 & 1.31 & 193.25 & 1.75 & 3.11 & 1.39 & 0.11 \\
\hline & F3 & 0.09 & 40.31 & 2.11 & 4.23 & 0.39 & 0.12 \\
\hline & F4 & 0.22 & 24.70 & 2.10 & 5.96 & 2.17 & 0.38 \\
\hline & F5 & 28.06 & 359.87 & 9.56 & 16.42 & 12.85 & 1.01 \\
\hline \multirow[t]{5}{*}{ S5 } & F1 & 0.82 & 85.27 & 0.12 & 0.72 & 0.01 & 0.06 \\
\hline & F2 & 0.93 & 137.18 & 1.02 & 1.81 & 0.98 & 0.14 \\
\hline & F3 & 0.04 & 24.21 & 1.55 & 1.90 & 0.07 & 0.22 \\
\hline & F4 & 1.51 & 32.99 & 1.52 & 5.34 & 3.07 & 0.15 \\
\hline & F5 & 26.33 & 408.89 & 11.45 & 24.65 & 46.35 & 0.35 \\
\hline \multirow[t]{5}{*}{ S6 } & F1 & 1.01 & 91.29 & 0.17 & 1.44 & 0.01 & 0.09 \\
\hline & F2 & 1.24 & 132.21 & 1.81 & 4.36 & 1.69 & 0.16 \\
\hline & F3 & 0.01 & 24.50 & 1.76 & 5.35 & 0.16 & 0.20 \\
\hline & F4 & 0.48 & 25.83 & 1.57 & 6.55 & 4.12 & 0.38 \\
\hline & F5 & 36.21 & 468.77 & 12.36 & 16.24 & 26.27 & 1.32 \\
\hline \multirow[t]{5}{*}{ S7 } & F1 & 0.82 & 30.65 & $\mathrm{ND}^{\mathrm{a}}$ & 0.29 & 0.02 & 0.05 \\
\hline & F2 & 0.08 & 57.09 & 0.36 & 1.10 & 1.49 & 0.17 \\
\hline & F3 & 0.06 & 15.45 & 0.68 & 1.51 & 0.03 & 0.13 \\
\hline & F4 & 1.33 & 28.48 & 1.69 & 8.76 & 3.62 & 0.08 \\
\hline & F5 & 26.89 & 401.22 & 11.55 & 22.31 & 21.13 & 0.46 \\
\hline \multirow[t]{5}{*}{ S8 } & F1 & 0.23 & 112.29 & 0.12 & 1.26 & 0.03 & 0.07 \\
\hline & F2 & 1.44 & 200.91 & 2.36 & 4.51 & 1.03 & 0.13 \\
\hline & F3 & 0.03 & 44.25 & 2.02 & 4.97 & 0.06 & 0.21 \\
\hline & F4 & 1.34 & 31.88 & 2.02 & 7.43 & 2.79 & 0.18 \\
\hline & F5 & 32.01 & 621.36 & 16.23 & 28.56 & 30.44 & 0.66 \\
\hline
\end{tabular}

${ }^{\mathrm{a}} \mathrm{ND}:$ not detected. 
fraction. The concentration range was as follows: $\mathrm{Cd} 0.09-0.17 \mu \mathrm{g} \mathrm{g} \mathrm{g}^{-1}, \mathrm{Cu}$ $0.08-2.55 \mu \mathrm{g} \mathrm{g}^{-1}$, Co 0.36-2.36 $\mu \mathrm{g} \mathrm{g}^{-1}$, Ni 1.10-4.51 $\mu \mathrm{g} \mathrm{g}^{-1}$, Mn 57.09-200.91 $\mathrm{gg} \mathrm{g}^{-1}$, $\mathrm{Pb} 0.98-1.69 \mu \mathrm{g} \mathrm{g}^{-1}$. The proportion of this fraction in the total concentration was about $10 \%$ for $\mathrm{Cd}$ and $\mathrm{Co}, 0.3-5.4 \%$ for $\mathrm{Cu}, 3.2-12.8 \%$ for $\mathrm{Ni}, 1.9-8.3 \%$ for $\mathrm{Pb}$. The relative higher proportion was also found for element $\mathrm{Mn}$, which 10.7-27.2\% of total concentration occurred in the F2 carbonate fraction. Carbonates were regarded as inefficient metal carrier phases (Sigg, 1987), so high concentration of $\mathrm{Mn}$ in this fraction maybe result from the poor selectivity of the regent used for $\mathrm{Mn}$ and the dissolution of $\mathrm{Mn}$ in hydrous oxides.

Iron-manganese oxides (F3): It is well established that iron and manganese oxides exist as nodules, concretions, cement between particles, or simply as a coating on particles; these oxides are excellent scavengers for trace metals and are thermodynamically unstable under anoxic conditions. By controlling the Eh and $\mathrm{pH}$ of reagents, dissolution of some or all the metal-oxide phases can be released. In our experiment $0.1 \mathrm{M} \mathrm{NH} \mathrm{NH}_{4} \mathrm{OH} \cdot \mathrm{HCl}\left(\mathrm{HNO}_{3}, \mathrm{pH}=2.0\right)$ was used. A very small proportion $0.02-0.3 \%$ and $0.1-2.3 \%$ was found in this fraction for $\mathrm{Cu}$ and $\mathrm{Pb}$ respectively. Similar proportion range was found for $\mathrm{Co}(4.8-13.4 \%)$ and $\mathrm{Ni}$ (4.4-15.8\%). The variation of proportion distribution according to sampling sites for $\mathrm{Cu}, \mathrm{Co}$ and $\mathrm{Ni}$ was not significant. Compared to the exchange fraction and the carbonate fraction, proportion of $\mathrm{Cd}$ in the reduciable fraction increased (7.2-24.2\%) and the proportion of $\mathrm{Mn}$ decreased (2.7-6.6\%). It should be noticed that the distribution of $\mathrm{Cd}$ in the reduciable fraction with sampling positions varied evidently. The lowest proportion of $\mathrm{Cd}(7.2 \%)$ was found at $\mathrm{S} 4$ and the highest proportion $(24.2 \%)$ was found at S5. So significant difference exciting between the two neighbor sites indicate that S5 was influenced by anthropologic pollution more seriously.

Sulfides and organic matter fraction (F4): In sediments, trace metals may be associated with the organic matters, such as living organisms, organic coatings on inorganic particles and biotic detritus. Under the oxidizing conditions, the organic materials may be destroyed and the trace metals associated with them may be released into the environmental water system. Metals in this fraction are more stable and difficult to take part in the geochemical cycle. It is not to say that metals in this fraction do not pose threaten to environment. The metals in this fraction always act as a sink and reservoir for pollution. In this study, the small proportions of the total concentration were found in this fraction for $\mathrm{Cu}(0.7-5.7 \%)$ and $\mathrm{Mn}(3.0-5.3 \%)$ in the sediments from Haihe River. As to $\mathrm{Co}$ and $\mathrm{Pb}$, about $10 \%$ of the total concentration occurred in this fraction and the elative higher proportion occurred to $\mathrm{Cd}(8.7-28.0 \%)$ and $\mathrm{Ni}(15-28.1 \%)$. It was found that the higher proportion of the total concentration was present in this fraction in the lake sediments for $\mathrm{Co}, \mathrm{Ni}, \mathrm{Pb}$ and $\mathrm{Mn}$ each by Tokalioglu et al. (2000). That $\mathrm{Cu}$ occurred in forms of the stable organic complexes and the metal sulfides in the lake sediments was also indicated in his paper, but, in our study, only very small proportion $\mathrm{Cu}(0.7-5.7 \%)$ of $\mathrm{Cu}$ was in the sulfides and organic matter fraction.

Residue fraction (F5): Metals in the residue fraction are safer to environment for 
their lowest mobility and bioavailability. Primary and secondary mineral containing metals in the crystalline lattice constitute the bulk of this fraction. To leach elements in this fraction is more difficult, because the structure of the crystalline lattice must be destroyed sufficiently. In this experiment, the aim was obtained by using of a strong acid HF. The results showed that the metals studied could be extracted completely. From the sequential extraction results, most of the metals occurred in the residue fraction accounted for a large proportion of the total concentration except for $\mathrm{Cd}$. The results agree with the observation obtained by Martin et al (1998) who found that approx. $70-80 \%$ of the total $\mathrm{Ni}$ and $60 \%$ of the total $\mathrm{Cu}$ were in the residue fraction in the river sediments.

From this study, the proposed five-step sequential extraction procedure is reliable and repeatable. Although the influence of non-corresponding reagents on other sediment components can not be ignored during the whole sequential extraction procedure, the method can supply more information about the mobilization and bioavailablity of metals and can help us to understand the metal recycles further. The results of the experiment indicate that Haihe River was not polluted with studied heavy metals seriously with the moderate concentration and the large proportion of total concentration in the residue fraction, excepted for the element Cd.

Acknowledgments. This work was jointly supported by National Natural Science Foundation of China(20137010, 20205008) and Chinese Academy of Sciences(KZCX2-414)

\section{REFERENCES}

Forstner U, Wittmann GTW (1979) Metal pollution in the aquatic environment. Springer-Verlag, Berlin p. 486.

Kersten M, Forstner U (1986) Chemical fraction of heavy metals in anoxic estuarine and coastal sediments. Water Sci Technol 18: 121-130.Tessier A, Campbell PGC, Bisson M (1979), Sequential extraction procedure for the speciation of particulate trace metals. Anal Chem 51: 844-851.

Martin R, Sanchez DM, Gutierrez AM (1998) Sequential extraction of U, Th, Ce, La and some heavy metals in sediments from Ortigas River, Spain. Talanta 46: 1115-1121.

Sigg L (1987) Surface chemical ascpects of the distribution and fate of metal ions in lakes, Wiley Interscience, New York pp. 320-349.

Stalikas CD, Pilidis GA, Tzouwara-Karayanni SM (1999) Use of a sequential extraction scheme with data normalisation to assess the metal distribution in agricultural soil irrigated by lake water. Sci Tot Environ 236: 7-18.

Surija B, Branica M (1995) Distribution of $\mathrm{Cd}, \mathrm{Pb}, \mathrm{Cu}$ and $\mathrm{Zn}$ in carbonate sediments from the Krka river estuary obtained by sequential extraction. Sci Tot Environ 170: 101-1189.

Tokalioglu S, Kartal S, Elci L (2000) Determination of heavy metals and their speciation in lake sediments by flame atomic absorption spectrometry after a four-stage sequential extraction procedure. Anal Chim Acta 413: 33-40. 
Ure AM, Ph. Quevauviller, H. Muntau, B.Griepink (1993) Speciation of heavy metals in solids and harmonization of extraction techniques undertaken under the auspices of the BCR of the Commission of the European Communities. Int J Environ Anal Chem 51: 135. 